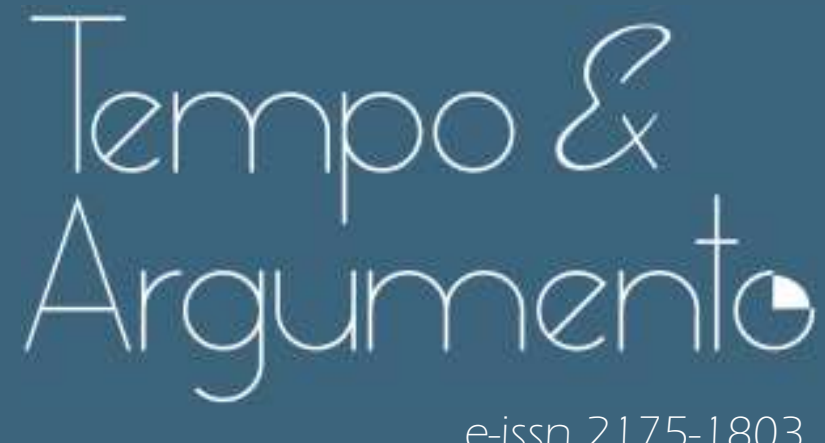

e-issn 2175-1803

\title{
A presença colonial no território palestino: uma reflexão historiográfica e testemunhal sobre os séculos XX e XXI na Palestina
}

Resenha da obra:

KHALIDI, Rashid. The Hundred Year's War on Palestine: A History of Settler Colonial Conquest and Resistance. London: Profile Books, 2020. Edição Kindle.

- Carolina Ferreira de Figueiredo

Doutoranda em História Social na Universidade Federal do Rio de Janeiro (UFRJ).

Rio de Janeiro, RJ - BRASIL

lattes.cnpq.br/8232598263921215

carolina.ferreirafigueiredo@gmail.com

(D) orcid.org/0000-0002-1054-9924

Para citar esta resenha:

KHALIDI, Rashid. The Hundred Year's War on Palestine: A History of Settler

Colonial Conquest and Resistance. London: Profile Books, 2020. Edição Kindle .

Resenha de: FIGUEIREDO, Carolina Ferreira de. A presença colonial no território

palestino: uma reflexão historiográfica e testemunhal sobre os séculos XX e XXI na

Palestina . Revista Tempo e Argumento, Florianópolis, v. 13, n. 33, e040 1.

maio/ago. 2021.

dol http://dx.doi.org/10.5965/2175180313332021e0401

Recebido: $13 / 11 / 2020$

Aprovado: 23/03/2021 


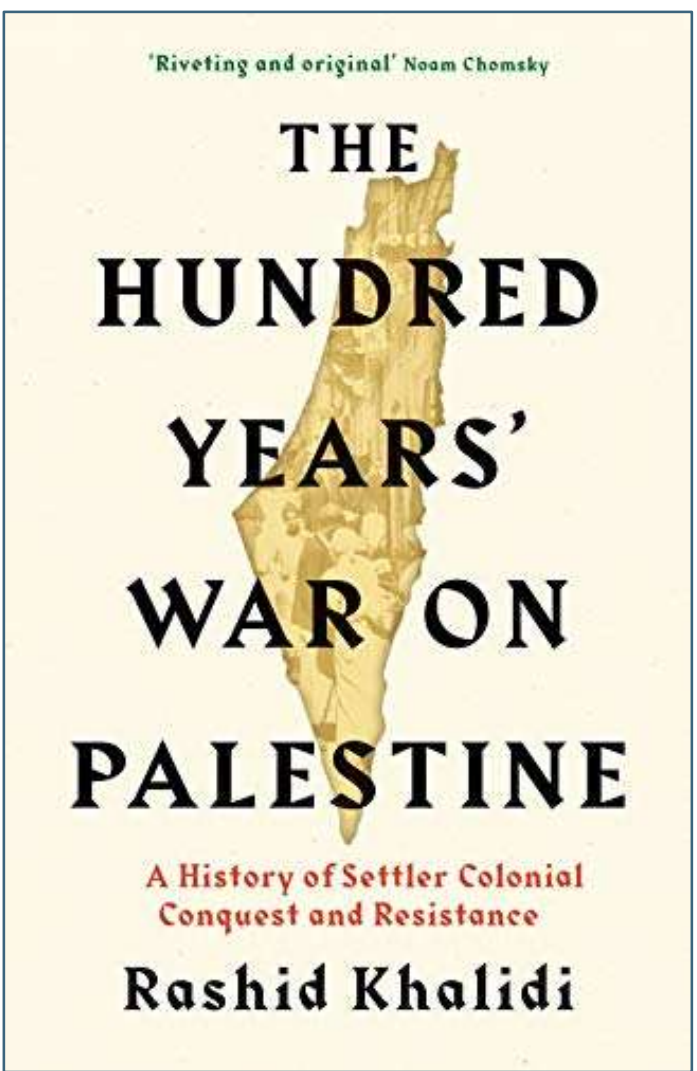

\author{
Resenha da obra: \\ KHALIDI, Rashid. The Hundred Year's \\ War on Palestine: A History of Settler \\ Colonial Conquest and Resistance. \\ London: Profile Books, 2020. Edição \\ Kindle.
}

A potente introdução de Rashid Khalidi neste livro, intitulado The Hundred Year's War on Palestine: A History of Settler Colonial Conquest and Resistance, em tradução livre, A Guerra de Cem Anos na Palestina: Uma História de Conquista Colonial e Resistência, demonstra elementos relevantes para a compreensão histórica da Palestina, ao mesmo tempo em que fundamenta questões historiográficas para o estudo da temática. Rashid Ismail Khalidi, palestino nascido em Nova Iorque em 1948, consolida-se como um dos maiores especialistas da área, atualmente ocupante da cadeira de Edward Said, professor da Universidade de Columbia, nos Estados Unidos, na área de Estudos Árabes. Autor de diversos livros e artigos que tratam da construção nacional palestina, Khalidi inova ao propor, como enfatiza, uma produção de pesquisa acadêmica junto às reflexões em primeira pessoa, ao incorporar lembranças de eventos que presenciou, bem como registros materiais, como fotografias e documentos, pertencentes a ele e a sua família. Ao abandonar a impessoalidade da escrita acadêmica, o historiador palestino aproxima o/a leitora/a à compreensão de momentos decisivos da história palestina contemporânea, traçando a importância testemunhal de sua família em diversas situações - como, por exemplo, a troca de correspondências entre seu tio Yusuf Diya al-Din Pasha alKhalidi e Theodore Herzl, fundador do Sionismo. Ao delinear essas relações, no entanto, o autor ressalta que a sua história não é única, mas compartilhada por milhares de palestinos/as. 
Do ponto de vista historiográfico, o livro traz novas dimensões ao propor, para cada um dos seis capítulos, o que denomina de pontos de inflexão (turning points), ou eventos, analisando os elementos que considera centrais para a conformação desta temporalidade de acontecimentos nos últimos cem anos da história da Palestina. Seguindo a sua proposta, Khalidi inicia a periodização a partir da Declaração de Balfour, de 1917, situando que este documento marca a delineação, de fato, do futuro Estado de Israel, com apoio da Inglaterra. Nesse sentido, no primeiro capítulo, intitulado The First Declaration of War, 1917-1939, ou A Primeira Declaração de Guerra, 1917-1939, o autor ressalta que na Declaração não há qualquer menção aos termos 'árabes' e 'palestinos' para se referir à comunidade existente, ainda que esta, naquele momento, fosse de aproximadamente 94\% da população total do território (p. 24). Em suma, a Declaração solidificou um discurso que reconhecia apenas a comunidade judaica, concluindo que o não reconhecimento da população nativa esteve na base da política e da 'questão' da Palestina, além de concebê-la como amorfa e ahistórica.

Nos capítulos dois e três, Khalidi aborda dois processos de ruptura histórica para os/as palestinos/as, tratando de 1948 e 1967, respectivamente; a criação do Estado de Israel e a ocupação militar dos territórios palestinos. Em ambos os capítulos, o autor discute mais intricadamente sobre o papel da Organização das Nações Unidas (ONU) nesses contextos. No capítulo intitulado The Second Declaration of War, 1947-1948, ou A Segunda Declaração de Guerra, 1947-1948, Khalidi, ao abordar o Plano de Partição proposto pela ONU em 1947, ressalta (1) a disparidade encontrada entre palestinos/as e Sionistas, tornando a resistência à migração cada vez mais difícil; (2) a complicada relação desenvolvida entre os países árabes, narrando um encontro impactante de seu pai com o Rei ‘Abdullah da então Transjordânia (p. 58).

O autor evidencia o caráter violento da criação do Estado de Israel, que ainda em 1947 iniciou a primeira fase do plano de conquista do território, resultando na limpeza étnica e na expulsão de cerca de 300.000 palestinos/as (p. 74). Com a criação de Israel, em maio de 1948, inicia-se uma segunda fase, marcada por confronto com os exércitos dos países árabes, e com 
A presença colonial no território palestino: uma reflexão historiográfica e testemunhal sobre os séculos XX e XXI na Palestina

Carolina Ferreira de Figueiredo

aproximadamente mais 400.000 habitantes expulsos da Palestina, incluindo os avós de Khalidi (p. 75). No capítulo três, intitulado The Third Declaration of War, 1967, ou A Terceira Declaração de Guerra, 1967, Khalidi discute a Guerra de Seis Dias e as consequências para as décadas seguintes. A atuação da ONU é acionada para discutir a Resolução 242, que tratava das diretrizes ao fim da curta guerra em 1967. Entretanto, como aborda, a resolução, ao estabelecer a 'devolução' dos territórios ocupados por Israel durante a guerra, normalizava a situação territorial e populacional inaugurada em 1948, além de criar uma ambiguidade sobre os termos da ocupação. Assim como na Declaração de Balfour, o autor destaca a ausência à menção aos palestinos/as, reforçando o argumento sobre o não reconhecimento da população. Por exemplo, o autor discute que a opinião pública estadunidense via o confronto de 1967 como uma ameaça ao desaparecimento de Israel.

Nos capítulos quatro e cinco, Khalidi foca a discussão sobre os partidos e organizações políticas de resistência, especialmente a Organização pela Libertação da Palestina (OLP), para compreender as relações com Israel e Líbano. Assim, The Fourth Declaration of War, 1982, ou A Quarta Declaração de Guerra, 1982 e quarto capítulo, trata do período específico da invasão de Israel ao Líbano, que objetivava expulsar a OLP, que por sua vez, havia constituído uma espécie de 'mini-estado' (p. 152) no país, e era o centro da organização de resistência. Nesse ponto, as tensões tornam-se complexas pela própria situação do Líbano, em guerra civil desde 1975. Neste capítulo, Khalidi relata a sua experiência - e de muitos - ao fugir dos ataques na capital Beirute, onde vivia na época.

No capítulo seguinte, intitulado The Fifth Declaration of War, 1987-1995, ou A Quinta Declaração de Guerra, 1987-1995, Khalidi discute o significado da Intifada, um movimento espontâneo de resistência à ocupação israelense surgido dentro do próprio território palestino da Cisjordânia, marcando uma organização popular local. A cobertura midiática da Intifada foi importante para mobilizar uma pequena mudança na opinião pública, que passou a ver a brutalidade do exército israelense para com jovens palestinos. Khalidi argumenta que esse cenário foi eficiente para que houvesse uma maior visibilidade dos efeitos da ocupação, ameaçando Israel como a OLP nunca conseguira. Esse movimento é tensionado 
A presença colonial no território palestino: uma reflexão historiográfica e testemunhal sobre os séculos XX e XXI na Palestina

Carolina Ferreira de Figueiredo

com a atuação da OLP, a partir de decisões diplomáticas, ao que o autor afirma enquanto erros da Organização e ingenuidade quanto ao real apoio dos Estados Unidos.

O século de guerra é delineado por Khalidi até o tempo presente, situando como a última "declaração de guerra" os ataques intermitentes à Gaza, no capítulo The Sixth Declaration of War, 2000-2014, ou A Sexta Declaração de Guerra, 2000-2014. Neste capítulo, o autor enfatiza dois processos: internamente, o surgimento e crescimento do Hamas, em oposição ao Fatah e a OLP, e externamente, a contínua influência dos Estados Unidos. Sobre os ataques à Gaza, Khalidi discute a desproporcionalidade do uso bélico de Israel em um pequeno território completamente sitiado. A partir da construção da linha temporal sobre a história da Palestina contemporânea, Khalidi fundamenta a compreensão em seu aspecto processual e de continuidade nas estruturas de dominação, expulsão e exclusão de palestinos/as do território.

A problemática central do livro direciona-se para a necessidade de se refletir acerca da natureza colonial no processo de constituição de Israel, que, segundo o autor, foi subestimada, e é fundamental para se compreender as qualidades típicas das campanhas para consolidar a posse da Palestina, especialmente a partir do não reconhecimento da população indígena e no emprego de uma retórica civilizatória, e com apoio da Inglaterra e Estados Unidos. Nesse sentido, o autor enfatiza que é possível pensar que o que ocorre na Palestina por mais de um século pode ser compreendido como um conflito colonial e nacional (p. 9). Ao partir para as conclusões, o autor ressalta que o movimento Sionista persiste em fazer o impossível, "impor uma realidade colonial em uma era pós-colonial” (p. 238), compreendendo que em 1947, às vésperas da criação de Israel, países como a Índia iniciavam o processo de independência colonial.

Ao citar Tony Judt, Khalidi afirma que o movimento Sionista chegou "tarde demais" (p. 238), e que embora tenha tido sucesso na implementação do Estado, o projeto inicial não foi concretizado, uma vez que os/as palestinos/as resistiram e persistem em lutar pelo direito ao território. Apesar dessa afirmação, que (possivelmente) denota um sentimento de esperança, ao situar o Sionismo como 
movimento cada vez mais insustentável, Khalidi reforça a característica colonial no tempo presente, demonstrando preocupação sobre o aumento do medo em relação à expulsão da população palestina.

Enquanto participante direto do circuito diplomático, Khalidi foca nas relações tecidas entre países do ponto de vista da política internacional, de modo a visibilizar as tensões entre os países árabes e, especialmente, a íntima relação entre Inglaterra e Estados Unidos com Israel. Embora discuta críticas de algumas decisões tomadas pelas organizações palestinas, o autor evidencia que o apoio quase incondicional dos Estados Unidos em relação à Israel torna a mediação comprometida, o que resulta na atual falta de reconhecimento dos direitos palestinos.

Outro ponto de reflexão sobre o Estados Unidos é a opinião pública e as percepções sobre a sua própria história, já que termos como ‘colono' ou 'pioneiro' têm conotações positivas dentro da história estadunidense (p. 241), reverberando na compreensão da constituição histórica de Israel, e contribuindo para o apagamento da população indígena dos territórios, tantos nos Estados Unidos quanto na Palestina. Nesse sentido, Khalidi se volta à reflexão do olhar colonial dentro da sociedade e da produção de conhecimento, sendo o reconhecimento dos indígenas americanos uma própria luta interna do país, e que, do ponto de vista epistemológico, tem ressonância na compreensão de outros processos, como o da Palestina.

O livro, então, é fundamental para o aprofundamento dos processos ocorridos na Palestina ao longo dos séculos XX e XXI, especialmente na compreensão da relação historicamente assimétrica entre palestinos/as, suas organizações representativas e o Estado de Israel. Ao incluir arquivos pessoais e familiares, o autor contribui para a reunião de fontes históricas e para a reflexão testemunhal, ao mesmo tempo em que analisa, enquanto pesquisador, os processos que marcam essa prolongada guerra, dialogando com as suas produções anteriores, como os livros Palestinian ldentity: the construction of modern national conciousness (1997) e Iron Cage (2007), e consolidando perspectivas acerca da divisão temporal e historiográfica sobre o tema. 
A presença colonial no território palestino: uma reflexão historiográfica e testemunhal sobre os séculos XX e XXI na Palestina

Carolina Ferreira de Figueiredo

Universidade do Estado de Santa Catarina - UDESC

Programa de Pós-Graduação em História - PPGH

Revista Tempo e Argumento

Volume 13 - Número 33 - Ano 2021

tempoeargumento@gmail.com 